\title{
De como ensinar: traços paradigmáticos nos manuais pedagógicos e perspectivas de investigação (1870-2015)
}

\section{On how to teach: paradigmatic traits in pedagogical manuals and research perspectives (1870-2015)}

\author{
Tânia Maria F. Braga Garcia* \\ Vivian Batista da Silva**
}

\begin{abstract}
RESUMO
O objetivo do artigo é contribuir para a produção de conhecimento sobre manuais destinados à formação de professores, focalizando particularmente as obras usadas no ensino de disciplinas como a Pedagogia, a Didática, a Metodologia e a Prática de Ensino, em perspectiva ainda pouco explorada na pesquisa educacional. Denominados de manuais pedagógicos, têm sido publicados no Brasil desde 1870 com a intenção de garantir aos futuros professores uma formação especializada. A complexificação da Didática como campo de conhecimento e o fortalecimento das Didáticas Específicas produziram transformações nesse conjunto de obras ao longo dos últimos quarenta anos, demandando revisões conceituais e novas perspectivas de investigação, apontadas pelas autoras nesta síntese realizada a partir dos resultados de suas pesquisas.
\end{abstract}

Palavras-chave: Manuais pedagógicos. Manuais didáticos. Didática. Formação de professores.

* Universidade Federal do Paraná. Programa de Pós-Graduação em Educação. Curitiba, Paraná, Brasil. E-mail: taniabraga@pq.cnpq.br. https://orcid.org/0000-0003-0614-290X.

** Universidade de São Paulo. Faculdade de Educação. São Paulo, São Paulo, Brasil. E-mail: vivianbs@yahoo.com. https://orcid.org/0000-0002-5509-2008. 


\begin{abstract}
The aim of the article is to contribute to the production of knowledge on manuals for teachers' education, focusing particularly on the books used in the teaching of disciplines such as Pedagogy, Didactics, Methodology and Teaching Practice, from a perspective still little explored in educational research. Called pedagogical manuals, they have been published in Brazil since 1870 with the intention of guaranteeing future teachers a specialized formation. The complexity of Didactics as a field of knowledge and the strengthening of Specific Didactics have produced transformations in this set of manuals over the past forty years, requiring conceptual reviews and new research perspectives, pointed out by the authors in this paper written based on their research results.
\end{abstract}

Keywords: Pedagogical manuals. Didactic manuals. Didactics. Teacher education.

\title{
O que sabem os professores? Notas introdutórias sobre os manuais que ensinam a ensinar
}

Como instaurar conhecimento científico numa área tão saturada de ideias e de certezas, quase sempre definitivas? Eis o que me levou a escrever, há quase dez anos, um livro chamado Evidentemente. Por que evidentemente? Porque em educação, tudo o que é evidente mente.

(António Nóvoa, Cartas a um jovem investigador em educação)

Não seria difícil, até mesmo entre os que não são especialistas em educação, encontrar algumas respostas para a pergunta formulada. Provavelmente, entre elas podem figurar o domínio de técnicas de ensino, o bom relacionamento com seus alunos, a execução das tarefas na escola e uma espécie de "dom" para o magistério. Para muitos, isso é praticamente evidente, como sugerido por António Nóvoa na epígrafe que inicia o presente artigo. Em uma "área tão saturada de ideias e certezas, quase sempre definitivas" (Nóvoa, 2015, p. 18), talvez valha a pena "desnaturalizar" evidências como essas, investigando os modos pelos quais se construiu aquilo que é tomado como parte importante dos conhecimentos docentes. O ideal de professor, escola, aluno, técnicas de ensino incorpora, de fato, a docência, mas não como elementos que sempre estiveram presentes com o mesmo sentido em que são entendidos hoje. Convém, então, 
identificar sua gênese e as configurações dos discursos que os sustentam e que fazem entranhar algumas representações entre nós.

Uma questão como essa pode conduzir aos manuais pedagógicos, porque eles são textos usados em cursos que ensinam a ensinar e, portanto, produzem e fazem circular conhecimentos da profissão (Silva, 2018). Eles poderiam ser chamados também de livros-texto ou de livros didáticos, por exemplo, pois se destinaram às aulas. Os títulos aqui considerados, já razoavelmente estudados no Brasil, em trabalhos como os de Garcia (2006), Hegeto (2014), Bastos (1998, 2011) e Silva (2018), e em outros países, por Roullet (2001), por exemplo, foram usados em disciplinas específicas do magistério, como a Pedagogia, a Didática, a Metodologia e a Prática de Ensino.

Desde que esses textos começaram a ser publicados no Brasil, na década de 1870, as disciplinas dirigidas à formação docente tiveram diferentes denominações, assumiram várias configurações e resultaram do esforço em garantir aos futuros professores, cada vez mais, uma formação pedagógica específica (Tanuri, 2000; Silva, 2018). Vistos geralmente como "produções menores", sintéticas e de fácil leitura, há que se reconhecer o papel fundamental desses manuais como iniciação ao magistério, reunindo parte substantiva dos conhecimentos a partir dos quais se configura a profissão.

Ora apresentando recomendações sobre como proceder em sala de aula, ora reunindo teorias de ensino, ideias de pedagogos, ora ensinando a usar técnicas de ensino, as obras que aqui interessam ainda são publicadas, em uma variedade de formas textuais que permanecem articuladas em torno de prescrições e compilações. Mas, atualmente, elas também incluem títulos que, sem seguirem os modelos clássicos de manuais, buscam outros formatos e incorporam reflexões e debates que evidenciam a complexificação da Didática como área de conhecimento (Hegeto, 2014). É nessa perspectiva que passam a ser publicados, desde os anos 2000 aproximadamente, livros destinados a cursos de formação de professores no formato de coletâneas, que reúnem diferentes vozes especializadas para falar de Didática aos iniciantes.

Ao tomar como objeto de estudo uma produção tão vasta, que inclui títulos publicados no decorrer de aproximadamente um século e meio, deve-se assinalar que, unidos pelo propósito comum de formar futuros professores, os manuais pedagógicos vêm assumindo formas e conteúdos variados, evidenciando uma riqueza de informações, especialmente quando surgem interrogações sobre os modos pelos quais os professores vêm sendo formados e quais são os seus conhecimentos. O que trazem as páginas dos manuais pedagógicos? Lições de como proceder em aula? Explicações sobre a natureza da criança? Recomendações de como proceder corretamente na escola? 
No âmbito da História da Educação, sem pretender efetuar uma revisão exaustiva das contribuições disponíveis, destaca-se que trabalhos como os de Vidal (2001), por exemplo, estimularam a pesquisa sobre materiais de leitura nas escolas normais, os quais colocavam em circulação determinados modos de ensinar, e que, assim, modelaram práticas de ensino na escola primária, e sobre os quais ainda pouco se conhecia no início da década de 2000. Carvalho e Vidal (2000) e Carvalho e Toledo (2006) estruturam seus estudos em torno da constituição do modelo escolar e do campo pedagógico no Brasil a partir de meados do século XIX e analisam obras que colocam em circulação tais modelos, destacando-se a análise das denominadas bibliotecas, coleções destinadas aos professores com vistas a sua formação e à difusão de inovações metodológicas requeridas por novas teorias.

Por outro lado, destaca-se a existência de contribuições que focalizam obras específicas. Primeiras lições de coisas: manual de ensino elementar para uso de pais e professores, de Norman Calkins, obra traduzida no Brasil, foi analisada por Teive Auras (2007) por ter sido adotada para orientar a implantação do método intuitivo em Santa Catarina, a partir de 1911. Segundo essa autora, isso converte o manual em um dos

elos fundamentais na conformação da identidade das professoras no período da Primeira República, contribuindo para incutir-lhes um corpo de categorias de pensamento e de ação necessários à missão que os republicanos lhes outorgaram: a de produzir o "cidadão racional" (...) entendido como aquele que respeita as leis, ama a pátria e confia no progresso social e científico. (Teive Auras, 2007, p. 79).

$\mathrm{Na}$ direção de contribuir para a compreensão do campo disciplinar da Didática, destaca-se a contribuição do estudo realizado por Mortatti (2001) sobre a obra Didática Minima, de Rafael Grisi, publicada em 1952. Segundo a pesquisadora, as análises sobre aspectos constitutivos da configuração textual da obra contribuem para "a compreensão do processo histórico da constituição da Didática como campo de conhecimento e como disciplina acadêmico-científica, no caso brasileiro (...) que se caracteriza pela permanência do caráter técnico, instrumental e normativo da Didática, o qual passa a ser questionado a partir dos anos de 1980" (Mortatti, 2001, p.15).

Alguns outros exemplos poderiam ser enumerados, como os estudos sobre autores que produziram manuais de orientação didática aos professores em formação ou em atuação nas escolas, como Afro do Amaral Fontoura e Theo- 
baldo Miranda Santos. Há pesquisas, mas ainda em pequeno número quando comparadas a outros recortes temáticos no campo da manualística (Escolano Benito, 2006). Contudo, entende-se que as referências destacadas nestas notas introdutórias cumprem a função de situar as potencialidades da pesquisa que se orienta em direção à análise desse tipo particular entre os manuais pedagógicos, os quais estão em pauta neste artigo pela focalização definida pelas autoras nesta contribuição ao dossiê temático.

Se durante décadas os manuais foram dirigidos a leitores específicos, particularmente alunos e alunas da Escola Normal (até a década de 1970) e do Curso de Magistério de Segundo Grau (com a Lei 5.692/71), também é preciso destacar que outras transformações ocorreram ao longo do tempo no que se refere aos leitores a quem os autores e editores se dirigem. Manuais destinados a orientar o ensino de disciplinas específicas, nos diferentes níveis e graus de ensino, também têm sido objeto de estudo para pesquisadores interessados em compreender os processos históricos relativos à formação desses professores, tomando os manuais como fontes para a pesquisa histórica; contudo, como alertam Bufrem, Schmidt e Garcia (2006), esses manuais também têm sido tomados como material empírico que possibilita compreender elementos do ensino das disciplinas, em abordagem didática e epistemológica, perspectiva encontrada em Carvalho (1999), Schmidt (2005) e, mais recentemente, em Urban (2009), Rodrigues Júnior (2015) e Nascimento (2014).

$\mathrm{O}$ texto que se apresenta neste dossiê tem origem nos resultados de pesquisas realizadas pelas autoras (Silva; 2018; Garcia, 2003, 2006, 2010; Garcia, Silva, Rodrigues Junior e Nascimento, 2019) em diálogo com outros estudos que analisam esses livros escolares em diferentes momentos de sua produção e circulação. Em particular, aqui serão privilegiadas as questões relacionadas ao âmbito da Didática Geral.

Nessa produção já relativamente ampla sobre os manuais pedagógicos, convém assinalar que os conhecimentos produzidos e reproduzidos em suas páginas consolidam, ao longo do tempo, o modelo de escola que começa a ser difundido mundialmente desde finais do século XIX. O objetivo central do texto é mostrar que os manuais de finais do século XIX e anos iniciais do século $\mathrm{XX}$ privilegiam as questões de organização da escola (matrícula dos alunos, condições do prédio, modelos de aula, entre outros elementos) e de definição do papel do professor, o que pode ser explicado pelo fato de que aquele era um momento inicial de ordenação dos sistemas escolares em cada país. Uma vez estabelecido certo consenso em torno das questões relativas à escola e ao professor, os manuais dos anos 1910/1920 passam a versar predominantemente sobre o aluno/criança, de modo a encontrar caminhos mais favoráveis à aprendizagem. 
Num terceiro momento, ao longo do século XX, fica evidente a progressiva especialização das metodologias de ensino, observando-se que é um momento em que há uma espécie de retorno do tom prescritivo assumido pelos manuais de fins do século XIX, mas com outras configurações, pois as questões de organização da escola estão, de certa forma, postas, assim como também se percebe o aluno/criança como ser cujas potencialidades devem ser respeitadas. Atualmente, os conteúdos dos manuais pedagógicos podem apresentar ênfases diferentes, ora evidenciando uma preocupação mais técnica, ora problematizando novas demandas temáticas, ou articulando questões que convidam ao debate, ou ainda reunindo textos de diferentes autores - multiplicidade de formas assumidas pelos manuais nas últimas décadas - e que sinalizam a complexificação da Didática como área de conhecimento científico e como disciplina escolar para a formação de professores.

Em suma, pode-se pensar em traços paradigmáticos que se materializam na configuração dos manuais estudados, ora atentos ao professor, à escola, ao aluno, às técnicas de ensino, ora aos temas e questões fundamentais da Didáticacomo a disciplina, a avaliação, a relação pedagógica. Como diria Roland Barthes a propósito dos livros de literatura, que nesse sentido guardam características comuns aos manuais que aqui nos interessam:

Se se lessem os manuais (...), não se teria nenhuma dificuldade em estabelecer desses traços a paradigmática, a lista opcional, a estrutura elementar, pois tais traços são pouco numerosos e me parecem obedecer perfeitamente a uma espécie de estrutura por pares oposicionais com, vez por outra, um termo misto; é uma estrutura extremamente simples. (1988, p. 54).

Ao ler os manuais pedagógicos, é possível apreender os conhecimentos entendidos como essenciais para os professores. Trata-se de uma espécie de "paradigmática", que será tratada a seguir nas seções deste artigo. Quais são os conteúdos desses livros e como eles se configuram ao longo do tempo? O que difere um antigo manual dos anos 1800 daqueles mais recentes, usados em pleno século XXI? Estariam todos preocupados com as técnicas de ensino? Insistiriam sempre no magistério como dom? Como representariam o aluno? De que maneira imaginariam a escola? Nos manuais pedagógicos, os processos de formação, ensino e aprendizagem são definidos de múltiplas formas, pois ora a figura do professor é privilegiada, ora é ocultada, assim como acontece com a figura do aluno. Pode-se situar quatro fases distintas na história desses 
livros, cada uma abrigando traços paradigmáticos específicos. Uma retomada de pesquisas já realizadas será necessária, já que o conjunto da produção é, hoje, razoavelmente consolidado, tanto entre brasileiros quanto também em outros países, como a França, a Espanha, a Alemanha e Portugal. Percorrendo o que se sabe sobre os modelos ou tradições de formação docente por meio dos manuais, pode-se - e assim se pretende - assinalar demandas e desafios aos pesquisadores interessados no tema.

\section{0-1890: o professor em destaque}

A história dos manuais pedagógicos começa, no Brasil, com livros como os de Antônio Marciano da Silva Pontes, o Compêndio de Pedagogia (1874). Vale lembrar, não é uma tradução nem foi escrito propriamente para os alunos das Escolas Normais. A essa altura, tais cursos ainda não estavam consolidados no país, considerando o número de instituições e a quantidade de pessoas então formadas (Tanuri, 2000). Os manuais do período, dos quais o de Pontes é exemplar, muitas vezes eram lidos por quem queria se preparar para os concursos públicos de ingresso na carreira.

O Compêndio foi feito para ser usado pelos seus alunos da Escola Normal de Niterói, a partir do programa de 1869, marcado pela preocupação em descrever aos normalistas não apenas os conteúdos da escola primária (relativos à leitura, à gramática, à escrita e doutrina cristã, à aritmética, à história sagrada, antiga, média e moderna), como também a forma de os ensinar. Essa ênfase articulou-se ao reconhecimento de que para lecionar foi preciso dominar os conteúdos e os modos de transmissão dos mesmos, compondo um modelo profissional diferenciado da imagem do antigo mestre-artesão, examinada por Villela (2000). A metodologia teve um lugar especial nesse currículo e correspondeu a um espaço de afirmação da especificidade do ofício docente. A organização interna do livro ${ }^{1}$ deu visibilidade ao esforço de formar as "boas" qualidades do professor, em suas

1 O Compêndio de Pedagogia (Pontes, 1881) apresentou a seguinte organização interna: a Primeira Parte tratou das Noções Preliminares e foi dividida em dois capítulos: Capítulo I: Definição, importância e fim da educação e Capítulo II: Qualidades de um bom professor. A Segunda Parte explicou os seguintes assuntos: Capítulo I: Da Educação, Capítulo II: Da Educação Moral e Capítulo III: Da Educação Intelectual. E a Terceira Parte foi composta por onze capítulos, assim designados: Capítulo I: Instrução, II: Metodologia Geral, III: Metodologia Especial, IV: Ensino da escrita, V: Método de aritmética, VI: Ensino de desenho linear, VII: Método de gramática, VIII: Ensino de Geometria Plana, IX: Da organização geral da escola, X: Da disciplina da escola e XI: Deveres do professor. 
dimensões intelectuais, físicas e morais. Estas últimas foram as mais destacadas para o exercício do magistério, incluindo doze virtudes: primeiramente, a gravidade; depois a discrição; a prudência; a bondade; a paciência; a firmeza; a modéstia; a polidez; o amor do retiro e do estudo; a exatidão e o zelo; a piedade e bons costumes e, por último, a vigilância (Villela, 2000).

O professor recebeu papel nuclear na dinâmica da escola, devendo "modificar os ímpetos maus da criança, assim como dirigir, conservar e firmar sempre mais as boas manifestações" (Passalaqua, 1887, p. 99). Representado como a principal personagem da escola, sua figura asseguraria todo o resto: o bom uso das metodologias, a boa manutenção da disciplina, a boa conduta dos alunos. É como se nesse primeiro momento tivesse sido construído um consenso em torno do significado do trabalho do professor, que pode nos parecer familiar até hoje.

\section{0-1910: o professor e a escola}

No segundo marco delimitado no estudo dos manuais pedagógicos, foi marcante o deslocamento da preocupação ontológica com a figura do professor para as representações que subordinam a sua atividade ao modelo de escola graduada. As Lições de pedagogia colecionadas por um "amigo da instrução" (Amigo da instrução, 1907) trazem exemplos significativos desse paradigma. De todos os manuais conhecidos até agora, esse é o único do qual não se sabe o nome do autor. Seus escritos enfatizavam a escola primária como "a mais poderosa cooperadora da civilização popular" (1907, p. 74). Dela dependem "todo o saber, todo o bem, todo o progresso. A criança ao deixar o regaço materno, exigem a moral e os interesses sociais, que se eduque e se instrua". Continua destacando que como não é possível existir um preceptor em cada família, "tornou-se indispensável uma instituição, com que se provesse ao impreterível cumprimento do dever inerente à paternidade: ensinar os filhos." (Amigo da instrução, 1907, p. 74. Grifos no original).

O docente foi definido como um dos profissionais responsáveis pela matrícula dos alunos e, também, por outras atividades burocráticas do tipo escrituração e correspondência escolar e o controle das passagens dos alunos entre as classes ascendentes da escola. Os manuais do período compreendido entre o final do século XIX e o início do século XX fizeram menção a essas tarefas, que posteriormente deixaram de ser enfatizadas. Provavelmente, isso pode ser explicado, em parte, pelo fato de que o desenvolvimento da escola ao longo 
do século XX contou com a incorporação de outros profissionais responsáveis pelo trabalho administrativo na escola.

Houve referências muito próximas acerca do modo individual de ensino, em que o professor deveria se dirigir a cada aluno por sua vez; ao modo mútuo, em que o professor contaria com os alunos mais "adiantados" da classe para ensinar aos mais "atrasados"; ao modo simultâneo, em que o professor reuniria todos os alunos num único grupo para eles participarem ao mesmo tempo da mesma lição da classe e, ainda, ao modo misto, aplicado no caso de as turmas serem muito numerosas e o professor encarregar alguns alunos "capazes" de ensinar os outros colegas. Acerca da escolha mais apropriada de um modo ou outro, os livros ensinaram ser preciso atentar para a natureza dos diferentes ramos do ensino primário, das diferentes idades dos alunos e do fim da instrução primária (Silva, 2018).

Se num primeiro momento da história dos manuais pedagógicos esses livros articularam a profissão docente a uma "vocação", essa ideia apareceu entre os anos finais do século XIX e o início do século seguinte associada à Pedagogia, vista como uma espécie de "auxiliar" à inteligência e iniciativa dos mestres ou a "ciência da educação", expressão repetidamente encontrada nos textos do período. Os manuais, nesse segundo momento de sua história, foram escritos durante um período crucial de construção do Estado-Nação e de estruturação do sistema escolar, quando se consolidaram, inclusive, os cursos de formação de professores primários. Os manuais pedagógicos brasileiros, além de outros publicados em países como Portugal (Silva, 2018) e França (Roullet, 2001), vincularam a Pedagogia a um campo de prática, central no plano de estudos das Escolas Normais.

\section{0-1940: conhecimentos mobilizados para a compreensão do aluno}

Durante as décadas iniciais do século XX, manuais pedagógicos mobilizaram conhecimentos no intuito de compreender os alunos. Exemplares desse paradigma foram a Introdução ao estudo da Escola Nova (Lourenço Filho, 1930), A Escola Nova comentada e explicada (Conte, 1932) e a Técnica da pedagogia moderna (Backheuser, 1934), reeditada posteriormente com o título Manual de pedagogia moderna (Backheuser, 1942). Ao explicarem os conhecimentos relativos ao aluno, os livros para normalistas construíram novas formas de conceber o ensino, articulando os seus conteúdos à Escola Nova. Este movimento já foi 
amplamente estudado por historiadores da educação (Nóvoa, 1995) porque os seus postulados foram apropriados em diversos lugares do mundo.

Lourenço Filho (1930), ao explicar o movimento escolanovista em seu manual, assinalou sua presença em vários países desde os últimos anos do século XIX. Atacada no discurso educacional do período "A escola tradicional antiga era [assim retratada nos manuais]: expositiva, dogmática, psitacista, verbalista, abstrata, dedutiva, intelectualista, artificial, anti-higiênica, anti-estética, triste, amedrontadora, etc. Em vez de permitir as perguntas, as objeções, a crítica, a discussão, impunha noções e sentenças indiscutíveis. Os alunos tinham que ouvir e aceitar calados" (Conte, 1932, p. 7).

$\mathrm{Na}$ chamada escola nova, as aulas deveriam ser organizadas de outra forma, atentando para o interesse do aluno, explicando o que teria valor e utilidade para sua vida. Reconhecia-se que um empreendimento dessa natureza "não foi obra nem de uma só pessoa nem de uma só época. [Isso] foi se delineando aos poucos, e resultou de um estudo atento da psiqué infantil, da vida real da criança, das suas tendências naturais, dos seus interesses em diversas idades, do estudo dos processos mentais do aprendizado natural, comparado ao da escola, etc." (Conte, 1932, p. 15). Os estudos permitiram "devolver a criança a si mesma, (...) fazê-la reingressar na vida d'onde a havia violentamente arrancado a escola. E foi o que fez a pedagogia nova. Se a vida infantil é experiência espontânea, curiosidade, observação, invenção, realização e brinquedo, por que não vazar o programa escolar nesses moldes? Por que não adaptar conhecimentos e educação aos gostos da criança?” (Conte, 1932, p.15).

A intensidade da circulação de conhecimentos foi a característica mais marcante na terceira fase da história dos manuais pedagógicos. Esses livros deram a conhecer a "grande geração pedagógica", suas proposições e contribuições para o campo educacional e para a constituição de uma Pedagogia renovada (Silva, 2018). Analisando os modos pelos quais a ideia de Pedagogia, ou de Ciência da Educação, configurou-se nos manuais do período, foram notáveis algumas distinções entre os níveis teórico e pragmático. Nesse sentido, Lourenço Filho organizou seu manual em duas partes, com uma primeira descrevendo as contribuições da Biologia, da Psicologia e dos Estudos Sociais para a escola. Além dessas páginas mais "teóricas", o autor dedicou alguns capítulos a questões didáticas o que, em suas palavras, "concorre para mais perfeita compreensão das relações entre modelos conceituais e modelos práticos" (Lourenço Filho, 2002, p. 219). Assim, o trabalho do professor não envolveu apenas a escolha de determinadas técnicas de ensino, mas exigiu, primeiramente, a "compreensão dos verdadeiros princípios da escola nova” (Lourenço Filho, 2002, p. 221).

A própria concepção de formação docente reconfigurou-se durante esse período no sentido de imprimir aos cursos um caráter menos propedêutico e 
mais profissionalizante (Nóvoa, 1987; Tanuri, 2000). Daí a ênfase em várias disciplinas, como Didática, Metodologia e Pedagogia, além de Psicologia Educacional, História da Educação e Sociologia Educacional. Até então, os manuais pedagógicos tinham se referido a temas restritos à Pedagogia e à Didática. Assim, a multiplicidade de temas ligados aos princípios que fundamentaram a prática docente na época articulou-se à história das Escolas Normais. De forma relacionada, convém lembrar mais uma vez que a Pedagogia passou por um esforço crescente de cientificação (Nóvoa, 1987), com o uso de conhecimentos provindos de outras áreas.

A figura do professor, enfatizada nos manuais de finais do século XIX e nos anos iniciais do século seguinte, foi praticamente apagada nessa terceira fase. Isso porque foi a representação de criança e de aluno que regulou os modos pelos quais o funcionamento da escola foi dado a ler nos manuais pedagógicos. A própria vinculação da Pedagogia com outras áreas do conhecimento, notadamente a Psicologia, foi justificada pela necessidade de se valorizar o educando.

Conforme autores como Nóvoa (1995) já assinalaram a respeito das produções educacionais do período, embora tivessem ocorrido mudanças nos modos de conceber a escola, a sua gramática não foi questionada, pelo contrário, confirmou-se a partir de argumentos mais detalhados, revestindo-se de um caráter científico. Não se questionou o valor de elementos da vida escolar já expostos em títulos publicados anteriormente. Ou seja, as qualidades do educador, a organização dos horários, os métodos de ensino, a disciplina, as punições e os castigos foram temáticas sempre tratadas, mas durante o movimento da Escola Nova esses aspectos permaneceram de uma certa forma esquecidos, pois foi assinalada a necessidade de se estudar o desenvolvimento do aluno. Assim, os manuais pedagógicos deixaram entrever, por um lado, a permanência dos elementos que compuseram a escola e, por outro, deram diferentes tipos de ênfase aos mesmos.

\section{0-1970: conhecimentos mobilizados para prescrever métodos de ensino}

Entre os anos 1940 e 1970, os manuais enfatizaram os métodos didáticos e privilegiaram a explicação de como planejar as aulas, ordenar os conteúdos, usar técnicas de ensino ou avaliar o rendimento dos alunos. Essa foi uma tendência da literatura educacional em nível mundial (Nóvoa, 1987) e, no Brasil, foi reconhecida como o movimento de "tecnicização do ensino" (Machado, 1980; 
Nagle, 1976). Depois dos anos 1940 e 1950, aproximadamente, o escolanovismo deixou de ser um tema privilegiado nos manuais e os escritos caracterizaram-se por argumentos mais sintéticos, prescritivos, desenvolvidos em parágrafos mais curtos e usando frases de fácil entendimento.

Essa mudança de ênfase relacionou-se com as modificações dos sistemas de ensino concretizadas depois da Segunda Guerra Mundial em várias partes do mundo (Nóvoa, 1987). No Brasil, por exemplo, o Estado criou condições para estender as oportunidades escolares a camadas cada vez mais amplas da população, que também reivindicaram possibilidades de acesso à educação formal (Beisiegel, 1984). Evidentemente, não só o número de escolas primárias, como também a quantidade de cursos de formação de professores primários, tenderam a crescer significativamente (Tanuri, 2000), impondo a reformulação nas maneiras de conceber, organizar e desenvolver o ensino.

Por outro lado, também a expansão da escola secundária e a necessidade de seu desenvolvimento produziram condições favoráveis para a elaboração de manuais destinados aos professores desse nível de ensino. Alguns estudos focalizam as contribuições da Campanha de Aperfeiçoamento e Difusão do Ensino Secundário - CADES, criada por meio do Decreto $n^{\circ} 34.638$, de 14 de novembro de 1953, com vistas a ações de formação docente e produção de materiais pedagógicos (Pinto, 2008). Embora não esteja no escopo deste artigo analisar materiais das didáticas específicas, deve-se registrar a intensa produção de orientações aos professores por meio de manuais pedagógicos nas diferentes disciplinas escolares (ver, por exemplo, Baraldi, 2016, na Matemática; Fonseca, 2003; Schmidt, 2006, na História).

Nessa perspectiva, os manuais dirigiram-se a um público maior e construíram um conteúdo mais acessível, por meio de protocolos de leitura dirigidos a leitores supostamente menos hábeis, iniciantes na área pedagógica. Os textos reduziram o trabalho dos docentes à aplicação de regras formuladas por teóricos e não pelos professores primários (Nóvoa, 1987). Assim, essa espécie de "tecnicização do ensino" só pode ser compreendida à luz das realidades sociais experimentadas no mundo e, mais especificamente, no Brasil - com a política desenvolvimentista do governo de Juscelino Kubitschek (Cunha, 1994) e a experiência ditatorial (Cunha e Góes, 1985).

No caso brasileiro, foi notável o movimento de expansão dos cursos nos mais diversos estados do país, acompanhado, consequentemente, pelo progressivo aumento de títulos destinados aos normalistas. Houve, ainda, uma boa parte dos manuais destinados simultaneamente aos mais diversos níveis de formação para o magistério, desde as Escolas Normais e Institutos de Educação, que prepararam docentes do ensino primário, até as Faculdades de Filosofia, 
que abrigaram os futuros professores do nível secundário ${ }^{2}$. Houve títulos que, originariamente, foram publicados em períodos anteriores, como os de Lourenço Filho, que, ao longo do século XX, continuaram a ser editados. O longo ciclo de vida de alguns títulos foi uma característica mais peculiar ao caso brasileiro, sugerindo que, nesse país, os manuais pedagógicos tenderam a ter um espaço de produção e circulação bem consolidado. As matérias tratadas nos manuais incluíram, além da Pedagogia e da Didática, as Metodologias e as Práticas de Ensino (Almeida, 1993).

Algumas publicações brasileiras do período foram as seguintes: os três volumes de Práticas escolares (D’Ávila, 1940-1962); a Metodologia do ensino primário (Santos, 1948); a Prática de ensino (Santos, 1948); as Noções de prática de ensino (Santos, 1951); os Fundamentos de educação (Fontoura, 1952); o primeiro volume da Pedagogia (D’Ávila, 1954); a Prática do ensino primário (Queirós e outras, 1954); a Didática mínima (Grisi, 1956). Ao afirmarem a Pedagogia, a Didática e a Metodologia como uma arte, os textos analisados retomaram, em certa medida, as inspirações dos primeiros manuais que vincularam o trabalho docente a uma espécie de vocação, agora pensada em termos de "arte educativa". Ao mesmo tempo, as produções do período remeteram para uma ideia consolidada no movimento da Escola Nova, que vinculou a Pedagogia à ciência e a Didática aos fins da educação. Nenhuma das dimensões foi negada de todo, nem a de arte nem a de ciência, contudo, elas se articularam em nome de uma redefinição da profissão docente.

No seu Sumário de Didática Geral, Luís Alves de Matos (1957) assinalou uma espécie de "intuição" do professor, dizendo que a determinação de qual seja a melhor maneira de ensinar "dependerá, em cada caso, do discernimento e da capacidade imaginativa e crítica do professor, sobrepondo-se à rotina e abrindo novos caminhos, mais consentâneos e racionais, para atingir os objetivos visados; dependerá, sobretudo, da sua capacidade para conceber nitidamente esses objetivos e firmar o equacionamento entre estes e os recursos e procedimentos adotados em aula" (Matos, 1957, p.14). O professor, o aluno e os conhecimentos estiveram, nessa perspectiva, subordinados à prática do ensino e da aprendizagem. Houve heranças deixadas pelo movimento da Escola Nova, relativas à importância que se deve dar ao aluno e ao papel do professor como um "auxiliador" do processo de aprendizagem.

2 Exemplo disso foi uma série de manuais escritos por Teobaldo Miranda Santos (1948; $1951 ; 1955 ; 1955 ; 1958 ; 1962 ; 1963 ; 1964)$ e publicados pela Companhia Editora Nacional junto à coleção intitulada Curso de Psicologia e Pedagogia, destinados, simultaneamente, a Escolas Normais, Institutos de Educação e Faculdades de Filosofia. 
Nas palavras de Nérici, as boas relações entre o professor e o educando são condição básica para toda e qualquer ação educativa, enfatizando que é fundamental o respeito à personalidade do educando, que "deve ser tratado como pessoa e não como número". Relembra que "os trabalhos escolares devem transcorrer em harmonia entre professor e educando, em sentido de trabalho em comum, de compreensão, simpatia e entusiasmo. (...) a ação do professor é insubstituível na ação educativa e (...) os bons resultados de um método dependem mais da atitude didática dele do que do próprio método" (1972, p. 42).

As articulações entre a Escola Nova e os planos de ensino legitimaram o planejamento prescrito aos professores. Isso porque a inspiração no escolanovismo funcionou como uma forma de justificar os elementos didáticos de um plano de ensino e ocultar o caráter técnico dos textos de formação dos professores, o que significou que as concepções de escolarização foram permanentemente traduzidas.

Enfim, a análise do conteúdo e dos argumentos veiculados nos manuais pedagógicos no decorrer de um século evidenciou as combinações entre os elementos da relação pedagógica estabelecidas de formas múltiplas e dinâmicas, variando ao longo do tempo. Em alguns momentos, os alunos ocuparam espaços secundários; em outros, os processos de ensino foram privilegiados; e ainda, em outros, a ênfase recaiu sobre as figuras dos professores e dos conhecimentos. Sem esse esforço, não teria sido possível criar certo "consenso" em torno da imagem de escola, "the one best system" (Tyack, 1974), muito visível depois da metade do século XX, quando os manuais já trataram do professor, do modelo escolar graduado, do aluno e dos meios tidos como mais eficazes para se alcançar o ensino e a aprendizagem. Os fios dessa corda discursiva (Nóvoa, $1995)$ entrelaçaram-se graças à circulação de ideias produzidas e apropriadas em diferentes momentos e espaços, compostos pelas várias combinações dos paradigmas construídos pelos manuais (Silva, 2018).

\section{De 1980 aos dias de hoje: pluralidade e complexidade da Didática nos manuais de formação}

$\mathrm{Na}$ linha de argumentação desenvolvida até aqui, sublinha-se que a Didática - enquanto disciplina escolar - está presente na tradição dos cursos de formação docente e os manuais são parte dessa tradição. Eles agregam um conjunto de conhecimentos da Pedagogia, da Didática e de outras disciplinas que se incluem na tradição de formação de professores e que, para Correia e 
Peres (2005, p. 196), podem ser situados como plataformas de observação de aspectos gerais ou globais que permitem, assim, "interrogar as modalidades de (re)criação do processo escolarizador e da cultura escolar nas vertentes histórica e sociológica".

No que se refere aos cursos de formação de professores secundários, isto é, na perspectiva da obtenção de licenciatura, a Didática já está presente como disciplina ou curso desde 1939. A partir de 1941, era ofertada após três anos de bacharelado, em um ano de formação específica para o ensino (Oliveira, 1993, p. 60). Como curso, sua abrangência incluía a Didática Geral e a específica, a Psicologia educacional, a Administração escolar, bem como fundamentos biológicos e sociológicos da educação. Mantida como disciplina nas faculdades de Filosofia, Ciências e Letras, a Didática deixou de incluir as didáticas específicas na década de 1960, quando as práticas de ensino em estágios supervisionados passaram a compor as disciplinas de formação pedagógica dos professores. Os manuais destinados aos professores produzidos nas décadas de 1950 e 1960 vão expressando essas mudanças na forma de compreender o campo da Didática. (Garcia, 2006).

As temáticas relacionadas com a Didática renovada, com os métodos ativos e com a direção da aprendizagem permaneceram presentes ainda na década seguinte, como se pode observar em obras como Didática para a Escola de $1^{\circ} e$ $2^{\circ}$ Graus, escrita por professores da Faculdade de Educação da Universidade de São Paulo e publicada no início dos anos de 1970. Por outro lado, a mesma obra inclui capítulos sobre a instrução programada - forma baseada nas teorias de Skinner e que privilegia o reforço como "o motor de aprendizagem" (Castro et al., 1972, p. 98) - e sobre o trabalho dirigido, entendido como atividade didática que promove "a capacidade de aprender a aprender, durante o exercício da própria aprendizagem" (p. 110) e como técnica de ensino individualizado (p. 125).

As reflexões de grande amplitude sobre o ensino, suas finalidades, seus métodos gerais e específicos foram substituídas pela exigência de planejamento e controle técnico das atividades no ensino e principalmente na aprendizagem, após o golpe que instaurou a Ditadura Militar no país (1964-1984), quando a Didática passa a se apoiar em pressupostos de uma "pedagogia tecnicista", procurando "desenvolver uma alternativa não psicológica, situando-se no âmbito da tecnologia educacional, tendo como preocupação básica a eficácia e a eficiência do processo de ensino" (Veiga, 1996, p. 35).

Algumas características dos conhecimentos veiculados por manuais no início da década de 1980 podem ser depreendidas da análise de uma obra intitulada Didática geral através de módulos instrucionais, escrita por Ângela Reis e Vera Joullié (1983, $4^{\mathrm{a}}$ edição). A obra se destina, segundo as autoras, tanto à formação de professores do nível médio (antigos cursos normais, que passaram 
a ser chamados de Cursos de Magistério a partir de 1971, na denominação de cursos profissionalizantes de segundo grau) como também do ensino superior. Para as autoras, "o grande aumento da população em idade escolar e a falta de professores qualificados" constituem-se em dois argumentos para a opção pela autoinstrução, na forma de módulos instrucionais, entendendo que com essa "metodologia" é possível "simplificar a tarefa do professor, reduzir-lhe o encargo" de tal forma que possa dar conta do que a sociedade lhe "cobra", mesmo com o "elevado número de alunos" sob sua responsabilidade. (p. 9).

Ainda na apresentação, as autoras destacam que a metodologia usada permite que o professor divida suas responsabilidades com o aluno, "elemento capaz de assumir funções" segundo os "estudos recentes de Psicologia". Em outras palavras, "é o próprio aluno o agente de sua aprendizagem" (p.9). Portanto, tem-se na apresentação os elementos que permitem identificar a proposta das autoras com o conjunto de orientações que predominava no Brasil naquele período. A expansão do sistema escolar pela ampliação da escolarização obrigatória definida na Lei de Diretrizes e Bases 5.692/71, sustentada no modelo de ensino com vistas à produtividade e eficiência, é elemento que subjaz às explicações fornecidas pelas autoras para justificar sua escolha pela autoinstrução (Garcia, 2006).

Os conteúdos dos cursos de Didática, nesse período, segundo Veiga (1996, p. 35), "centram-se na organização racional do processo de ensino, isto é, no planejamento didático formal, e na elaboração de materiais instrucionais, nos livros didáticos descartáveis". Para esse modelo, a elaboração de módulos instrucionais na perspectiva da autoinstrução se revela, de fato, como uma opção adequada. E a obra é exemplar no uso do modelo, abordando os temas clássicos da Didática sob a linguagem das novas exigências técnicas.

A análise realizada (Garcia, 2006) evidenciou que, na perspectiva das autoras, os conhecimentos da docência - ou habilidades - são mais bem aprendidos "em pequenas etapas". Cada etapa, cada exercício, cada texto responde a uma necessidade de organização lógica e cumpre seu papel no esquema geral traçado, objetivado no fluxograma apresentado pelas autoras (p. 17) que registra o ponto de partida (a Entrada), as etapas sequenciadas e a finalização do processo - se Aprovado, Saída; se Não aprovado, Realização de atividades para sanar deficiências. Assim, tem-se, no fluxograma, a expressão exemplar das características dessa "metodologia que elimina o fracasso", em que se entrelaçam as ideias de domínio e de competência e que permite "uma avaliação minuciosa, segura e profunda de cada objetivo previsto", garantindo ao professor um alto grau de controle nas "falhas específicas" e, consequentemente, a proposição de "atividades terapêuticas". 
A análise mais detalhada da obra se justifica uma vez que contribui para explicitar o movimento ocorrido a partir da década de 1980 no campo disciplinar e nos manuais pedagógicos. As transformações, decorrentes do "modelo sóciopolítico brasileiro fundado no binômio desenvolvimento-segurança nacional e do modelo de educação como fator de desenvolvimento social" (Oliveira, 1993, p. 30), demarcaram a existência de uma profunda crise na disciplina nos anos de 1980, conforme apontado por autoras como Oliveira (1993) e Veiga (1996). A década, então, foi marcada pelo discurso da necessidade de uma "reconstrução" da Didática, para superar o enfoque instrumental que se tornara sua característica mais acentuada.

No campo de produção dos manuais para professores, as duas últimas décadas trouxeram transformações significativas. O estudo dessa produção demanda esforços de pesquisadores e de grupos, seja em razão da quantidade de manuais destinados à formação e orientação dos professores, seja em função de sua diversidade. No campo da Didática Geral, Hegeto e Garcia (2014) identificaram um grande número de obras publicadas nas duas últimas décadas (em torno de 50 títulos), entre os quais se encontram algumas obras reeditadas sucessivamente, como a Didática Geral, de Claudino Piletti, e a Didática, de José Carlos Libâneo. Segundo as autoras, ambas as obras mantêm uma estrutura de conteúdo e forma clássicos nesse tipo de manual, contemplando conhecimentos ligados à organização do ensino (planejamento, seleção de conteúdos, avaliação, por exemplo), apresentando capítulos temáticos com algum grau de articulação. Contudo, as transformações na sociedade brasileira demandaram a inclusão de novas temáticas, que vêm sendo contempladas pelos manuais - por exemplo, a questão da multiculturalidade e dos direitos humanos, que incluiu diferentes sujeitos sociais na temática referente ao aluno, à criança, ao adolescente.

Ao lado desse modelo, muitas obras apresentam-se na forma de coletâneas, com múltiplos autores e temas. São exemplares as obras Ensinar a Ensinar: Didática para a escola Fundamental e Média, organizada por Amélia D. de Castro e Ana Maria P. Carvalho (2001), Lições de Didática, organizada por Ilma Passos A. Veiga (2006) e Didática e docência: aprendendo a profissão, organizada por Isabel Maria S. de Farias (2009). O que isso pode significar em relação aos conhecimentos da docência postos em circulação por esse outro tipo de manual?

Analisando o primeiro desses manuais, Hegeto e Garcia (2014) destacam que na primeira parte, intitulada "Reflexões sobre a Didática", alguns autores discutem o objeto da disciplina - o ensino - e tratam de algumas relações entre a Didática e a Escola, o Currículo e a Aula. Para as autoras, essa forma de organização "reflete os debates no campo do currículo desde a década anterior [1990], que recolocou questões ao campo da Didática, expressos na obra como 
um espaço de reflexão que antecede a apresentação da segunda parte, intitulada "A Didática em ação"" - onde os temas relativos ao trabalho dos professores são focalizados pelos autores (Hegeto e Garcia, 2014, p. 28).

Pode-se ler, nesse tipo de manual, a expressão de recusa à ideia de que bastam apenas as "habilidades técnicas" - presente em manuais das décadas de 1970 e 1980 - e a tentativa de um diálogo entre a produção científica do conhecimento didático e o espaço da construção das práticas docentes. As mudanças no sistema educativo ocorridas a partir da década de 1990, decorrentes da Lei de Diretrizes e Bases da Educação Nacional (LDBEN), Lei n. 9.394, de 20 de dezembro de 1996, situaram-se em espaços nos quais a defesa de formação de todos os professores em nível superior se somava à valorização dos conhecimentos da experiência, apontando perspectivas de maior aproximação entre a universidade e a escola básica - marca desses manuais referidos.

Tem-se, então, novas perspectivas em relação aos conhecimentos necessários ao exercício da docência. Se por um lado mantêm-se em circulação algumas ideias que podem ser encontradas em manuais antigos - embora com ares renovados - centradas na prescrição de modelos e procedimentos técnicos, por outro lado constata-se a circulação de conceitos como professor reflexivo, professor pesquisador e pesquisa em colaboração, cujos campos conceituais, também sujeitos a questionamentos e debates, situam a figura do professor em espaços de maior autonomia e de maior qualificação na produção do conhecimento sobre o ensino.

Para além dessa transformação no âmbito da Didática Geral, a análise dos manuais nas últimas décadas evidencia que o fortalecimento das discussões de ordem metodológica que foi observado a partir da década de 1940 resultou na produção de um elevado número de títulos no campo das Didáticas Específicas - identificados usualmente como manual de metodologia de ensino -, muitos deles voltados aos professores dos anos iniciais, mas também a professores especialistas nas diferentes disciplinas escolares. O estudo desses manuais é ainda um fértil espaço a ser explorado pelos pesquisadores.

A valorização dos conhecimentos disciplinares, especialmente a partir das reformas curriculares estaduais que sucederam o final da Ditadura Militar, e posteriormente as orientações curriculares emanadas do Governo Federal a partir da década de 1990 encontram correspondência com o crescimento do número de manuais destinados a orientar os professores nas atividades de ensino. Isto pode ser tomado como evidência do fortalecimento do campo metodológico nas obras para professores, mas também de uma maior complexidade no campo da Didática, nas suas relações com a epistemologia. No caso da História, que recuperou seu espaço curricular específico desde os anos iniciais do ensino fundamental (antes ocupado pelos Estudos Sociais), Rodrigues Júnior (2015) localizou 20 manuais destinados a orientar os professores no ensino da disciplina. 
Deve-se destacar que, a partir desse levantamento e das análises realizadas, foi possível identificar diferentes estruturas nesses manuais. Assim, Rodrigues Júnior e Garcia (2016) estabeleceram uma categorização dos manuais de Didática da História em quatro tipos, que, segundo os autores, representam diferentes formas usadas pelos autores para dialogar com os professores, embora todas elas produzidas com a finalidade de, em alguma medida, orientar suas práticas de ensino. Há manuais que dialogam com o professor por meio de reflexões sobre o ensino; outros dialogam com o professor indiretamente por meio de relatos de experiência de ensino; um terceiro tipo é formado por manuais que dialogam com o professor de forma direta sobre a organização do ensino, enfatizando linguagens específicas a serem utilizadas, como os quadrinhos ou as imagens; e finalmente aqueles que dialogam com o professor de forma direta e explícita sobre a organização do ensino por meio de uma estrutura didática específica, estes últimos denominados como manuais didáticos em sentido estrito, em uma tentativa de particularizá-los entre os manuais pedagógicos.

Pesquisar os usos desses manuais nos cursos de Pedagogia, por exemplo, pode ser um percurso para aproximar-se dos efeitos da circulação desses manuais contemporaneamente. No caso da Didática da Física, Nascimento e Garcia (2019) têm desenvolvido estudos sobre obras para orientar o ensino de conhecimentos físicos nos anos iniciais. As autoras identificaram manuais que circularam ao longo do século XX, constatando que tais orientações aparecem dede o início do século, em obras com diferentes características: Manuais de Didática Geral, mas que também incluem orientações para o ensino de diferentes disciplinas escolares - é o caso da Didáctica (Nas escolas primárias), de João Toledo (1930); dos Manuais de Metodologia do Ensino ou de Prática de Ensino, que apresentam orientações gerais e também orientações quanto aos conhecimentos específicos; dos Manuais de Didática das Ciências, localizados desde a década de 1950 e, mais recentemente, de Didática da Física, tanto para os anos iniciais como para outros níveis de ensino.

As pesquisas e os manuais destacados nesta seção devem ser entendidos como elementos indiciários da fertilidade do campo temático no qual as autoras têm situado parte significativa dos seus trabalhos, tanto os individuais como aqueles compartilhados com outros pesquisadores e grupos, mas também com alunos em diferentes níveis de formação para a pesquisa. As referências e exemplos não poderiam ter a pretensão de esgotar o conjunto de contribuições que têm sido dadas pelos trabalhos voltados a compreender as relações entre os manuais pedagógicos e a constituição dos conhecimentos da docência, mas são provocadores de desafios e de novas perguntas sobre o que se ensina aos professores. 


\section{Notas finais}

Em suma, o que podemos extrair dessas descrições paradigmáticas? Antes de mais nada, elas vão se configurando nas páginas dos manuais pedagógicos de diferentes formas. Nem sempre as técnicas de ensino foram enfatizadas, como ocorreu nas décadas de 1960 e 1970 . Nem sempre se exaltaram as qualidades morais do docente, como os livros mais antigos fizeram. A figura do aluno começou a ser mais destacada nos anos iniciais do século $\mathrm{XX}$, mas nem sempre foi assim.

A literatura destinada aos cursos de Pedagogia e Licenciatura, hoje, evidencia as reflexões e questões relevantes da área. Observa-se uma estabilização de temas e debates já presentes nos anos anteriores e a inclusão de novas problemáticas demandadas pelas transformações ocorridas na sociedade brasileira e pela própria complexificação da Didática enquanto campo científico e disciplina escolar. Longe de serem evidentes, os conhecimentos do magistério, compilados nas páginas dos manuais aqui estudados, assumem múltiplos sentidos e configurações e constituem-se em estímulo e desafio para a continuidade das pesquisas.

\section{REFERENCIAS}

ALMEIDA, J. A escola normal paulista: estudo dos currículos (1846 a 1990) - destaque para a Prática de Ensino. Boletim do Departamento de Didática, Araraquara: UNESP, ano XI, n. 9, 1993.

AMIGO DA INSTRUÇÃO. Lições de pedagogia colecionadas por um "amigo da instrução”. Rio de Janeiro: Livraria Francisco Alves, 1907.

BACKHEUSER, E. Manual de pedagogia moderna. Porto Alegre: Livraria Globo, 1942.

BARALDI, I. M. A CADES e a formação de professores para o ensino Secundário: uma campanha nos anos de 1950-1960. In: ENCONTRO NACIONAL DE PESQUISA EM HISTÓRIA DA EDUCAÇÃO MATEMÁTICA, 3., 2016. Anais do $3^{\circ}$ Encontro Nacional de Pesquisa em História da Educação Matemática: história da educação e formação de professores. São Mateus: SBHMat, 2016, p. 34-43.

BARTHES, R. O rumor da língua. São Paulo: Brasiliense, 1988.

BASTOS, M. A formação de professores para o ensino mútuo no Brasil: o "Curso normal" para professores de primeiras letras do Barão de Gérando (1839). Revista História da Educação, v. 2, n. 3, p.95-119, jan.-jun. 1998. 
BASTOS, M. Manual para os Jardins de Infância: ligeira compilação pelo Dr. Menezes Vieira -1882. PA: Redes Editora, 2011.

BEISIEGEL, C. Educação e sociedade no Brasil após 1930. In: FAUSTO, B. (Org.). História geral da civilização brasileira: o Brasil republicano - economia e cultura (1930-1964). São Paulo: Difel, 1984. p. 381-416.

BUFREM, L. S.; SCHMIDT, M. A.; GARCIA, T. B. Os manuais destinados a professores como fontes para a história das formas de ensinar. Revista HISTEDBR On-line, Campinas, SP, v. 22, p. 120-130, 2006.

CARVALHO, A. L. P. Geomorfologia e Geografia Escolar: o ciclo geográfico Davisiano nos manuais de Metodologia de Ensino (1925-1993). 1999. Dissertação (Mestrado em Geografia) - UFSC, Florianópolis, 1999.

CARVALHO, M. M. C. Manuales de pedagogía, materialidade de lo impreso y circulación de modelos pedagógicos en el Brasil. Revista Colombiana de Educación, v. 52, p. 91-136, 2007.

CARVALHO, M. M. C.; VIDAL, D. G. (Org.). Biblioteca e formação docente: percursos de leitura (1902-1935). Belo Horizonte: Autêntica, 2000.

CARVAlHO, M. M. C.; TOLEDO, M. R. A. A Biblioteca da Educação de Lourenço Filho: uma coleção a serviço de um projeto de inovação pedagógica. Quaestio (UNISO), v. 8, p. 47-63, 2006.

CASTRO, A. F. D. et al. Didática para a escola de $1^{\circ}$ e $2^{\circ}$ graus. São Paulo: Pioneira/ MEC, 1972.

CONTE, A. A Escola Nova comentada e explicada. São Carlos: Raça Editora, 1932.

CORREIA, A. C. L.; PERES, E. Aprender a ser profesor a través de los libros: representación profesional, currículum escolar y modelos de aprendizaje en los manuales de Pedagogía y Didáctica para la formación de profesores de enseñanza primaria en Portugal (1870-1950). In: GUEREÑA, J. L.; OSSENBACH, G.; POZO, M. M. (Dir.). Manuales escolares en España, Portugal y América Latina (siglos XIX y XX). Madrid, ES: UNED Ediciones, 2005. p. 196-213.

CUNHA, L. A.; GÓES, M. O golpe na educação. 2. ed. Rio de Janeiro: Jorge Zahar, 1985.

CUNHA, M. V. A dupla natureza da Escola Nova: psicologia e ciências sociais. Cadernos de Pesquisa, n. 88, p. 64-71, fev. 1994, p.64-71.

ESCOLANO BENITO, A. Curriculum editado y sociedad del conocimiento. Texto, multimedialidad y cultura de la escuela. Valencia: Tirant lo Blanc, 2006.

FONSECA, S. A. O Ensino de História nas páginas da revista "Escola Secundária". In: ENCONTRO NACIONAL DOS PESQUISADORES EM ENSINO DE HISTÓRIA, 6., 2003, Londrina. Londrina, 2003. 
GARCIA, T. B. Ciência do ensino e doutrina do método: a didática e os manuais para formação de professores nas escolas normais (1890-1990). In: CONGRESO IBEROAMERICANO DE HISTORIA DE LA EDUCACIÓN LATINOAMERICANA, 6., México. México: Colegio San Luis/CESUNAM/SOMEHIDE (1), 2003, p. 1-14.

GARCIA, T. B. "Esquemas de trabalho para o domínio dos conhecimentos": módulos instrucionais de Didática Geral para formar professores na década de 1980. In: CONGRESSO IBEROAMERICANO DE LA EDUCACIÓN LATINOAMERICANA, 2006. Argentina: Sociedade Argentina de Historia de la Educación, 2006, p. 1-23.

GARCIA, T. B. Do “como ensinar" ao "como educar": elementos do código disciplinar da Didática Geral no manual de João Toledo (1930). In: CONGRESSO LUSO-BRASILEIRO DE HISTÓRIA DA EDUCAÇÃO, 8., 2010. São Luís: EDUFMA, 2010.

GARCIA, T. B. Criteria used by teachers in Brazilian elementary schools in the process of textbook selection. Orbis Scholae (Online), v. 8(2), p. 9-2, 2014.

GARCIA, T. B.; SILVA, V.; RODRIGUES JÚNIOR, O.; NASCIMENTO, F. E. Manuals for teacher education in Brazil. Research perspectives. In: RODRÍGUEZ RODRÍGUEZ, J.; GARCIA, T. M. B.; BRUILLARD, E. (Eds.). IARTEM 1991-2016: 25 years developing textbook and educational media research. Kongsberg: IARTEM, 2019, p. 257-273.

HEGETO, L. de C. F. A Didática como disciplina escolar: estudo a partir dos manuais de Didática Geral. 2014. Tese (Doutorado) - PPGE-UFPR, Curitiba, 2014.

HEGETO, L. de C. F.; GARCIA, T. B. Significados da Didática como disciplina escolar nos manuais de Didática Geral. Olhar de Professor, v. 17, n. 1, p. 20-36, 2014.

LOURENÇO FILHO, M. B. Introdução ao estudo da Escola Nova. São Paulo: Melhoramentos, 1930.

LOURENÇO FILHO, M. B. Introdução ao estudo da Escola Nova. 14. ed. Rio de Janeiro: Ed. UERJ/Conselho Federal de Psicologia, 2002.

MACHADO, N. J. O tecnicismo e a hipertrofia do psicopedagógico. Cadernos PUC, n. 3 , p. $11-27$, mar. 1980 .

MATOS, L. A. de. Sumário de Didática Geral. Rio de Janeiro: Editora Aurora, 1957.

MORTATTI, M. R. Entre o ideal e o usual: a Didática Minima de Rafael Grisi. Rev. Bras. Est. Pedag., Brasília, v. 82, n. 200/201/202, p. 15-25, jan./dez. 2001.

NAGLE, J. Educação e linguagem: para um exame do discurso pedagógico. São Paulo: EDART, 1976.

NAGLE, J. Educação e sociedade na Primeira República. São Paulo: Edusp, 2009.

NASCIMENTO, F. A construção de uma didática da Física: contribuição dos manuais de orientação aos professores. 2016. Dissertação (Mestrado) - Universidade Federal do Paraná, Setor de Educação, Programa de Pós-Graduação em Educação. Curitiba, 2016. 
NASCIMENTO, F. E.; GARCIA, T. B. Didática da Física: contribuições dos manuais para a constituição de uma disciplina escolar. In: SIMPÓSIO NACIONAL DE ENSINO DE FÍSICA - SNEF, 23., 2019. Disponível em: https://sec.sbfisica.org.br/eventos/snef/ xxiii/programa/searchAutor.asp. Acesso em: 10 ago. 2019.

NÉRICI, I. Introdução à didática geral. Rio de Janeiro: Editora Fundo de Cultura, 1960. NÓVOA, A. Le temps des professeurs. Lisboa: INC, 1987.

NÓVOA, A. Uma educação que se diz nova. In: CANDEIAS, A.; NÓVOA, A.; FIGUEIRA, M. Sobre a educação nova. Lisboa: Educa, 1995. p. 25-41.

NÓVOA, A. Carta a um jovem investigador em educação. Investigar em educação Revista da Sociedade Portuguesa de Ciências da Educação, n. 3, p. 13-22, 2015.

OLIVEIRA, M. R. A reconstrução da Didática: elementos teórico-metodológicos. Campinas, SP: Papirus, 1993.

PASSALAQUA, C. Pedagogia e metodologia (teórica e prática). São Paulo: Tipografia a vapor de Jorge Seckler \& Comp., 1887.

PINTO, D. C. Campanha de Aperfeiçoamento e Difusão do Ensino Secundário: uma trajetória bem-sucedida? In: MENDONÇA, A. W.; XAVIER, L. N. (Orgs.). Por uma política de formação do magistério nacional: o INEP/MEC dos anos 1950/1960. Brasília: Instituto Nacional de Estudos e Pesquisas Educacionais Anísio Teixeira, 2008. (Coleção INEP 70 anos, v. 1)

PONTES, A. M. da S. Compêndio de pedagogia. 3. ed. Niterói: Tipografia Fluminense, 1881.

REIS, Â.; JOULLIÉ, V. Didática geral através de módulos instrucionais. 4. ed. Petrópolis, RJ: Vozes, 1983.

RODRIGUES JÚNIOR, O. Os manuais de Didática da História no Brasil (1997-2014): entre tensões e intenções. 2015. Tese (Doutorado em Educação) - Programa de Pós-Graduação em Educação da Universidade Federal do Paraná, Curitiba, 2015.

RODRIGUES JÚNIOR, O; GARCIA, T. B. Manuais de didática da história: contribuições para entender suas especificidades. Antíteses, v. 9, n. 18, p. 275-297, jul./dez. 2016.

ROULLET, M. Les manueles de pédagogie (1880-1920). Paris: Presses Universitaires de France, 2001.

SCHMIDT, M. A. "O Método é a maravilha da escola e a delícia do professor". Os manuais didáticos e a construção da prática de ensino de História. In: GUEREÑA, J.; OSSENBACH, G.; POZO, M. (Dir.). Manuales escolares em España, Portugal y América Latina (Siglos XIX e XX). Madrid: Universidad Nacional de Educación a Distancia-UNED, 2005, p. 215-231.

SCHMIDT, M. A. Estado e construção do código disciplinar da Didática da História. Perspectiva, v. 24, n. 2, p. 687-706, jul./dez. 2006. 
SILVA, V. B. Saberes em viagem nos manuais pedagógicos: construções da escola em Portugal e no Brasil (1870-1970). São Paulo: UNESP, 2018.

TANURI, L. História da Formação de professores. Revista Brasileira de Educação, 2000, v. 14, p. 61-98.

TEIVE AURAS, G. Manual de lições de coisas de Norman Calkins: operacionalizando a forma intuitiva de ensinar e de aprender. Sarmiento, v. 11, p. 79-92, 2007.

TOLEDO, J. Didáctica nas escolas primárias. São Paulo: Livraria Liberdade, 1930.

TYACK, D. B. The One Best System: A History of American Urban Education. Cambridge, Mass.: Harvard University Press. 1974.

URBAN, A. C. Didática da História: percursos de um código disciplinar no Brasil e na Espanha. 2009. Tese (Doutorado) - PPGE-UFPR, Curitiba, 2009. Disponível em: http:// www.ppge.ufpr.br/teses/D09_urban.pdf. Acesso em: 10 ago. 2019.

VEIGA, I. P. Didática: uma retrospectiva histórica. In: VEIGA, I. (Coord.). Repensando a Didática. Campinas, SP: Papirus, 1996. p. 25-40.

VIDAL, D. G. O exercício disciplinado do olhar: livros, leituras e práticas de formação docente no Instituto de Educação do Distrito Federal (1932-1937). 1. ed. Bragança Paulista: EDUSF, 2001.

VILLELA, H. Da palmatória à lanterna mágica: a Escola Normal da província do Rio de Janeiro entre o artesanato e a formação profissional (1868-1876). 2000. Tese (Doutorado) - FEUSP, São Paulo, 2000.

Texto recebido em 31/07/2019.

Texto aprovado em 01/09/2019. 